\title{
Research on College English Online Teaching During Covid-19 Outbreak
}

\author{
$\mathrm{Si} \mathrm{Li}^{1, *}$ \\ 1 School of Foreign Languages, Dalian Neusoft University of Information, Dalian, Liaoning, China \\ *lisi@neusoft.edu.cn
}

\begin{abstract}
With the outbreak of Coronavirus Pneumonia China and even the world are stepping into the Online Teaching era, which altered traditional classroom teaching. This paper analyzes the opportunities and challenges that online teaching is faced with and explores the path and experiences of college English online teaching from the perspectives of classroom activities design, teaching resources production, extracurricular self-autonomous learning activities design, assessment (mainly formative assessment), classroom management. It may provide College English educators with reference through the exploration of online teaching platform and collection of pedagogical experience.
\end{abstract}

Keywords: Online teaching, blended teaching, College English, stop lecture non-stop learning

\section{新冠肺炎疫情期间高校英语课程在线教学经验探析}

李思 $1, a$

${ }^{1}$ 大连东软信息学院外国语学院, 大连, 辽宁, 中国

alisi@neusoft.edu.cn

\section{摘要}

突如其来的疫情打乱了原有的线下教学节奏，使中国乃至全世界 “不得不” 进入在线教学时代。本文 以当前新冠肺炎疫情期间为背景，分析了在线教学面临的机遇与挑战，从课堂活动设计、教学资源制 作、课外自主学习活动设计、课程考核、课堂管理五个维度探索了大学英语课程线上教学的路径和经 验。通过对于线上教学平台的探索, 以及线上教学经验的总结, 希望为英语教育工作者提供借鉴思路。 关键词: 在线教学, 混合式教学, 大学英语, 停课不停学

\section{1. 研究背景}

2019 年 12 月开始, 中国开始流行一场大规模传染 病一一新型冠状肺炎 (Coronavirus Pneumonia)。2020 年 2 月末, 全国大中小学寒假结束后, 教育部宣布应对 新冠肺炎 “停课不停学” 方案。由此, 全国大中小学不 得不进入 “网络教学” 时代。

每次应对 “灾难” 都拉动了中国互联网和移动互联 网的跨越式发展, 2003 年 “抗击非典” 催化了网上购物 等电子商务的快速发展, 2008 年 “汶川地震救灾” 催化 了移动互联网的快速发展。2020 年这场 “抗击新冠肺炎 疫情” 必将催化 $5 \mathrm{G}$ 深刻改变社会。作为教育工作者, 我们要思考 $5 \mathrm{G}$ 、智能化、云化将催生和加速教育的创新 变革, 线上工作教学、在线学习成为趋势, 新科技应用 将让个人和社会组织减少对时间依赖、空间限制、工作 方式限定。
2019 年 9 月, 大连东软信息学院大学英语教学开始 推行混合式教学模式, 线上、线下相结合, 经过了第一 学期的教学, 师生们渐渐适应混合式教学与学习模式。 2020 年 3 月开学初, 因疫情, 师生们开始居家办公、学 习, 将混合式教学进一步应用到实践中。本研究旨在探 索疫情期间大学英语课程在线教学的方式和经验, 期望 为混合式教学的实践提供一个范本。

\section{2. 在线教学面临的机遇与挑战}

对于教师来说, 在线教学意味着必须要熟悉新工具 和新手段，离开了传统的黑板、粉笔和讲台，开始通过 网络平台进行知识的传授与讲解，如何熟练应用网络授 课平台, 比如钉钉、腾讯会议、雨课堂, 对于大学英语 教师, 尤其是对老教师来说, 是第一个挑战。第二, 由 于大学英语课程属于语言类课程, 如何开展线上教学活 
动和进行有效的课堂互动是个需要关注的问题。第三, 采用何种授课方法, 是传统的讲授法、语法翻译法 [1], 还是现代的交际教学法 [2]、任务型教学法 [3] 等进行线 上教学, 在线下教学过程中如何指导学生, 是老师们需 要探索和总结的。虽然遇到了诸多挑战, 但是疫情期间 不得不居家授课, 对于广大教师来说也是一个将混合式 教学理论应用于实践的一个好机会。

对于学生来说, 进行线上学习需要具备一定的硬件 和软件环境。硬件上, 包括居家时是否有电脑, 手机, $\mathrm{PAD}$, 或者家里的网速, 手机流量等因素。软件上, 学生 能否从思想上接受在线授课, 按照老师的要求进行课前 及课后的自主学习与复习, 是课上有效学习的必要条件。 [4] 线上教学的第三周结束后, 公共英语教学部对大连 东软信息学院 2018 级和 2019 级学生开展了在线教学第 三周 “学生学习状态、学习体验” 调查, 通过问卷星, 共收到有效问卷 4206 份。其中， 31.41\%的学生反映能 够自我调整并迅速恢复学习状态; 53. 66\%的学生反映在 逐渐适应线上学习, 逐渐恢复学习状态; 但还有 $15.65 \%$ 的学生反映在线学习环境复杂, 导致学习状态不理想或 者无法投入学习。总体来说, 大部分学生 (84.35\%) 进 入到了网络学习状态。

\section{3. 大学英语在线教学经验}

开展在线教学五周后, 公共外语教学部组织教师填 写了在线教学经验分享调查问卷, 从课堂活动设计、教 学资源制作、课外自主学习活动设计、课程考核 (含形 成性考核)、课堂管理, 共五个维度, 收集老师们的线上 教学经验。

\section{1. 课堂活动设计}

教师是学习活动的设计者和支持者 [5], 在线教学 对于语言口语类或者写作类任务的讲评, 教师可以通过 课前选取具有典型问题的任务样例, 在课前推送进班级 学习群, 学生以小组为单位在课前进行讨论, 课中通过 学生互评的形式, 排查样例中存在的相关发音、语法等 问题, 并对样例如何进一步改善给出意见。最后由教师 进行总结点评, 学生展示与学生互评的形式加强了学生 对于课堂活动的参与, 使学生在审视别人存在问题的过 程中提高自身语言能力, 小组讨论的形式也增强了学习 中的朋辈互助。

在课堂活动设计方面, 由于在线教学互动受到限制, 设计的活动要比课堂教学略微容易一些, 让学生积极参 与, 获得成就感。同时, 在讨论类题目设计的时候, 为 了使更多的学生课上参与进来, 可以将题目课前布置给 学生, 并将题目要求细化。

在线上讲授时, 为了使学生注意力集中, 讲授时间 要比课堂教学简短一些。可以安排小组讨论活动, 但不 宜过多, 尤其是大班英语教学。

\section{2. 教学资源制作}

因为学生缺少纸质教材, 授课过程中学生也无法看 到教师的动作, 所以语言类课程课件的制作必须更加详 细、图文并茂, 才能让学生快速找到教师讲授的重点, 也便于学生的理解。通过在 PPT 中插入视频、音频、设 置动画效果等, 强化授课效果, 让学生的思路跟教师保 持一致。此外, 每讲授完一个知识点就穿插一些习题, 通过钉钉群的投票功能、课堂派的课堂互动功能辅助完 成。

针对学生课前、课中和课后的学习内容, 可以制作 课程学习手册, 学生通过阅读学习手册了解本科重难点, 同时配以课前习题, 学习过程习题, 以及课后测验等部 分内容, 做到一册多用, 避免学生因资源过于分散而不 能有效利用的问题。该手册学生可以留存作为后续复习 使用, 用途丰富, 且电子版便于留存。大连东软信息学 院公共英语教学部为学习《大学英语听说强化》课程的 同学制作了课程导学 (单元主题导入视频)、单元学习指 南 (电子手册)、教学微视频 (词汇与语法自学微课)、 教学课件 (课文自学版本) 等课程资源资源。(表一)

\section{表 1 《大学英语听说强化》课程资源}

\begin{tabular}{|l|l|}
\hline 课前 & $\begin{array}{l}\text { 学习通 (单元主题导入视频、词汇微 } \\
\text { 课、自学课件) }\end{array}$ \\
\hline 课后 & $\begin{array}{l}\text { iTest 系统 (听力、阅读、翻译) } \\
\text { Fif口语训练系统 (口语) } \\
\text { 批改网 (写作) }\end{array}$ \\
\hline
\end{tabular}

\section{3. 课外自主学习活动设置}

课外学生的自主学习直接影响在线课堂的学习效 果, 自主学习任务要适量, 不要过多, 应与课堂的教学 知识点紧密相关, 并且有及时的反馈, 最好在课堂上利 用一下时间反馈, 能够调动学生的积极性。为此, 大连 东软信息学院公共英语教学部利用学习通平台 (图一) 为学生上传课前学习资料, 包括课程相关词汇微课、教 学课件等, 让学生自主预习, 课中对学生课前学习内容 及时检测、对课后在作业反馈, 课后通过 iTest 系统布 置听力与阅读作业, Fif 口语训练系统布置口语练习, 批改网布置写作作业。在学生进行课外自主学习活动时, 老师们也会根据学生的课上学习状态和授课进度适时 地调整自主学习内容, 比如提出 iTest 系统中的阅读选 词填空题可以不做, 从而给学生的课外自主学习减压。 


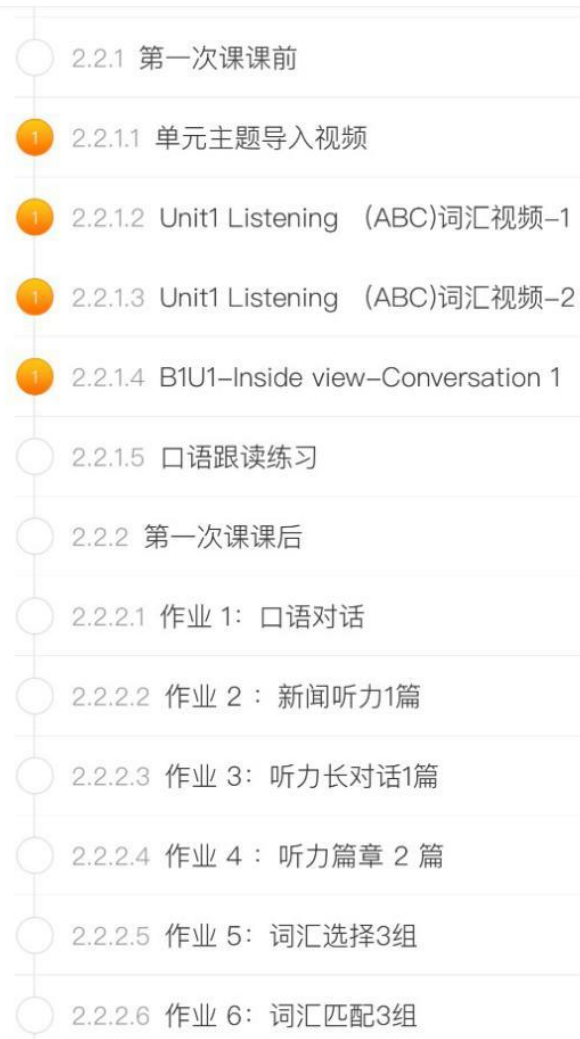

图 1 学习通平台

当课程内容为能力考试辅导教学内容时, 为了培养 学生应考时的时间观念, 难免需要边练边讲、甚至在规 定时间内完成整套习题的做法。考虑到课上时间有限, 有的老师会规定学生在课下自行完成习题, 课上以讲题 为主。线上教学期间, 学生在家里学习, 干扰因素较多, 很难保证能够在 1 个半小时到 2 小时内心无旁鳌, 一 鼓作气完成一套习题。鉴于此, 可以在讲每套习题的前 一晚，召集班内同学集体进行线上晚自习，规定时间、 规定做题内容, 要求学生统一打开视频, 在任课教师的 监督下完成一整套试题。教师在 “监考” 的同时, 可以 同时完成备课, 也不觉得浪费了课外时间。这样, 第二 天课上讲题的时候, 学生对考题内容记忆深刻, 同时也 锻炼了做题速度和专注力。另外, 如果有教师认为, 组 织全班同学自习难度较大, 可以将全班分成若干小组, 并指派小组长, 在组长的带领下, 组员自行商量自习做 题时间，相约线上共同在规定时间内完成整套习题。

\section{4. 课程考核}

考核环节是线上授课最难控制的环节, 如何尽量为 学生创造一个公平的测试环境成了在线考核的关键。在 考查学生对于单词的理解和应用时, 可以利用课堂派, 以课文中的句子为载体, 在句子中把想要考的单词空出 来, 同时给出单词的首字母, 让学生把单词填写完整。 为了最大程度的避免学生在考核期间查阅资料, 在正式 发布考试之前, 让个别学生试做, 计算出不查阅参考资
料的情况下所需要的最短时间, 设置答题时间。这样考 核出来的结果基本符合学生平时的状态和老师的预期。 在线直播教学过程中课堂测验如何避免学生作弊, 考查出学生的实际学习效果, 是保障在线课堂教学效果 的重要环节。《商务英语视听说 (二)》课程的做法是所 有的课堂测验内容全部是教材外的素材, 学生无处可以 抄袭, 同时采用问卷星用手机微信扫码答题, 规定提交 时间, 屏蔽搜索引擎, 同时要求学生摄像头对对准个人 答题角度, 这样全方位无死角的杜绝作弊。

形成性考核的设计上, 重视学生在线学习课堂表现 的考核, 《大学英语听说强化 (二)》课程是将 60 分的形 成性考核分为口语作业 (10 分), 随堂验收 (10 分), 阶 段性检查 (30 分) 与能力测试 (10 分)。口语考核是根 据学生在Fif 口语训练系统句子、段落的朗读完成情况, 和口语考试模拟题完成情况, 参考系统自动评分, 教师 抽查, 复听, 按照学生的发音、语音、语调以及口语作 业完成的态度等维度进行打分。随堂验收注重学生自主 学习效果检测, 教师根据各自班级实际教学及学习任务 安排, 针对每次课前学生的线上学习效果随堂进行检查、 验收, 内容可以是单词听写、词汇练习、口语对话展示、 听力练习、句子翻译等。阶段性检查分为三次: 1 . 第一 次检查是课前在线学习情况, 课中在线学习效果和课后 作业完成情况的考核 (10 分); 2 . 检查二是以音频和视 频形式提交的口语会话或单元口语项目成果物, 教师根 据学生提交的成果物, 检查学生口语项目的完成情况 (10 分); 3. 阶段性检查三是 iTest 测试, 对教材所学 的内容进行检验, 检查听力、词汇、阅读和翻译等内容, 教师随堂举行。最后的 10 分能力测试是凯思能力测试, 考核学生的语言运用能力。

\section{5. 课程管理}

对于口语课程的线上教学, 尤其是大班授课, 课堂 管理是个难度较高的问题。因为授课班型较大, 主动回 答问题的学生总是那些, 而其他大部分学生, 在线上授 课的情形下, 教师无法得知他们是否在听讲, 所以可以 采用提问的方式 “无规律” 变化的方式, 比如抢答加分, 随机点名提问, 按顺序提问, 或同学推荐。这样可以营 造一定的课堂紧张度, 帮助学生保持注意力和良好的听 课状态。

在大班口语课授课前, 可以将课上需要讨论的口语 题目提前布置给学生, 让学生课前查阅资料。学生课堂 分组讨论, 教师可以加入个讨论组, 可以作为 “观察 员”, 观察学生小组讨论, 也扮演 “讨论者”, 加入学 生的讨论。在线教学教师加入讨论组就像是真是课堂中 教师在学生小组讨论的时候在课堂中来回走, “巡视”。 一方面监控学生的讨论进度, 另一方面可以为有问题的 小组答疑解惑。

课堂管理中的课堂互动设计, 可以要求学生在在线 平台组群内, 通过打字完成与老师的课堂互动。教师端 通过手机打字进行互动, 电脑端保持屏幕分享, 平台远 程讲解, 互不影响。此方法可以最大限度的使尽量多的 
学生参与课堂, 也避免了在线教学只能单名同学逐一发 言的限制, 课堂气氛会比较活跃。另外, 为了鼓励学生 多多互动, 可以对群内发言次数进行统计, 并给与相应 次数对应的加分到学生的平时成绩考核中去。

\section{4. 结语与展望}

混合式教学与翻转课堂的教学模式提高了学生的 学习积极性和自主学习的体验感。但是, 如果教师没有 做好课前、课中和课后的设计、准备与检测工作, 很难 保证在线教学会有传统教学的教学效果 [4]。此外, 疫情 结束后, 高校外语工作者还应思考: 如何将课堂教学与 疫情期间线上、线下教学衔接, 提升混合式教学效果。 疫情期间, 线上线下混合式教学模式得到了迅速推广, 疫情后线上课程建设会迎来一个新的高峰。如何建设高 校大学英语课程, 使其课程体系与传统教学有效衔接。 如何建设国家级-省级-校级的 MOOC (Massive Open Online Courses), SPOC (Small Private Online Courses), 微课等丰富的线上课程资源。如何建设和完 善混合式教学平台, 使其更好地服务于线上线下教学, 以及如何提升和改善教学工具的使用, 提升教师的教学 效果和丰富学生的学习体验。

\section{REFERENCES}

[1] J. Harmer, The Practice of English Language Teaching, Longman, 2007.

[2] J. C. Richards, T. H. Rodgers, Approaches and Methods in Language Teaching, Cambridge University Press, 2001.

[3] R. Ellis, Task-based language teaching. Cambridge: Cambridge University Press, 2003.

[4] Yang, H.J., Zhang, H.P., Cheng, P. (2020) Research on college online teaching during the outbreak of new coronavirus pneumonia. China Journal of Multimedia \& Network Teaching., 04:194-196.

[5] Yu, S.Q., Wang, H.M.(2020) How to better organize online learning in extreme situations such as epidemics. China Educational Technology. 05: 6-14 